\title{
Lifetime gains of host-feeding in a synovigenic parasitic wasp
}

\author{
D. GIRON, S. PINCEBOURDE and J. CA S A S
}

Institut de Recherche sur la Biologie de l'Insecte (Centre Nationale de la Recherche Scientifique, Unité mixte de Recherche 6035), Faculté des Sciences, Université de Tours, France

\begin{abstract}
Understanding behavioural decisions relative to host use for feeding or reproduction by foraging parasitoids requires not only the study of metabolic pathways followed by nutrients, but also the quantification of lifetime fitness gains of each alternative behaviour. By using a combination of observational and manipulative approaches, the lifetime host-feeding gains are measured both in terms of fecundity and longevity in the parasitoid Eupelmus vuilletti. Host-feeding increases both egg production and longevity. The increase in fecundity is mainly determined by the amount of lipids obtained whereas the lifespan extension is mainly determined by carbohydrates. Proteins obtained through host-feeding have been implicated previously in egg production by parasitoids but protein intake has no effect on fecundity and longevity in E. vuilletti. The amount of nutrients gained through host-feeding and invested in eggs is variable and changes over the lifetime of the animal. Therefore, lifetime feeding gains are best understood through the construction of dynamical budgets running over the entire lifespan of an insect.
\end{abstract}

Key words. Foraging ecology, host-feeding, life-history strategies, lifetime fitness gains, parasitoids, reproduction, survival.

\section{Introduction}

Dynamic state models have been used extensively as a powerful technique in evolutionary ecology to make detailed predictions about the optimal behavioural decisions of organisms such as parasitoid wasps (Chan \& Godfray, 1993; Collier et al., 1994; Godfray, 1994; Heimpel et al., 1994, 1998; Collier, 1995; Roff, 2002). In turn, these behavioural models play an important role in predicting the population dynamics and stability of host-parasitoid interactions and the outcome of biological control efforts (Kidd \& Jervis, 1989; Murdoch, 1990; Kidd \& Jervis, 1991b; Krivan \& Sirot, 1997). Parasitoids search the environment for hosts, usually other insects, in which to lay their eggs. However, reproduction is not the only way to use the host. Indeed, in many species, female parasitoids use the host for feeding, instead of ovipositing. Even though con-

Correspondence: D. Giron, Entomology Department, University of Georgia, Athens GA 30602, U.S.A. Tel.: +1 706583 8238; fax: +1 706542 2279; e-mail: giron@bugs.ent.uga.edu current host-feeding and oviposition are sometimes observed, it is usually assumed that host-feeding kills the host or reduces its quality as an oviposition site (Jervis \& Kidd, 1986; Heimpel \& Collier, 1996). Thus, on finding a host, a female parasitoid makes a series of behavioural decisions, such as whether or not to renounce the opportunity for current reproduction (oviposition) in favour of anticipated chances for future reproduction (host-feeding). These decisions are inevitably associated, at least in part, with physiological thresholds. Theoretical studies have shown that the optimal behavioural decision relies heavily on the nature and function of host-feeding (Jervis \& Kidd, 1986; Mangel, 1989; Chan, 1991; Kidd \& Jervis, 1991a; Houston et al., 1992; Chan \& Godfray, 1993; Collier et al., 1994; Collier, 1995; Heimpel et al., 1998). Whether nutrients obtained from host feeding are employed for egg production, maintenance, or both, has consequences for the way in which parasitoids partition their time and energy between reproduction and feeding activities (Chan \& Godfray, 1993; Rivero \& Casas, 1999a). The incorporation of physiological realism into models of parasitoid behaviour and population dynamics has thus raised a series of new questions 
concerned with the pattern of resource allocation to egg production and metabolic maintenance in relation to adult diet in females.

Adult nutrition can have important effects on lifetime reproductive success of female parasitoids (e.g. Hagan, 1986; Jervis et al., 1996). Under natural conditions, synovigenic parasitoid species may exploit both host haemolymph and nonhost foods such as nectar, honeydew and, to a lesser extent, pollen (Leius, 1961; Jervis \& Kidd, 1986; Jervis etal., 1992, 1993; Heimpel \& Collier, 1996; Jervis et al., 1993, 1996; Jervis \& Kidd, 1996; Gilbert \& Jervis, 1998; Jervis \& Kidd, 1999). Current knowledge of the effects of adult feeding on lifetime reproductive success is fragmented and ambiguous, both with respect to intractable differences in the experimental conditions and interspecific differences in the nature and quantity of the nutrients consumed (Heimpel \& Collier, 1996; Heimpel etal., 1997; Rivero \& Casas, 1999a; Giron etal., 2002). Most studies have examined the relationship between sugar feeding and longevity or the effect of host-feeding on fecundity (mainly under conditions of unlimited sugar availability) (reviewed by Heimpel \& Collier, 1996). Experiments in which the effect of different adult diets on fecundity and longevity are compared suggest that, for many host-feeding species, sugars that occur naturally in nectar or honeydew increase longevity, and that host-feeding provides materials for egg maturation (reviewed by Jervis \& Kidd, 1986 and Heimpel \& Collier, 1996). However, the effect of host-feeding on lifetime reproductive success is a question that has remained largely unaddressed, because only a limited number of studies exist in which the lifetime host-feeding gain (in terms of fecundity and longevity) has been empirically quantified (Heimpel et al., 1994, 1997; Collier, 1995).

The positive correlation between host-feeding and fecundity is well established (Doten, 1911; Flanders, 1935; Bartlett, 1964; Jervis \& Kidd, 1986; Heimpel \& Collier, 1996). The clearest case is for anautogenous species in which the parasitoid emerges with no mature eggs and host-feeding must precede oviposition to ensure egg production (Jervis \& Kidd, 1986). Recent studies using direct tracking of radioactively-labelled amino acids (obtained by host-feeding) into eggs confirm a direct link between hostfeeding behaviour and incorporation of the nutrients in eggs (Rivero \& Casas, 1999b; Rivero et al., 2001). However, few studies have tried to quantify the value of a single hostfeeding meal in terms of the number of eggs produced (Heimpel et al., 1994, 1997; Collier, 1995).

The effect of host-feeding on parasitoid longevity has received much less attention than the effect on fecundity. However, in certain species, such as Eupelmus vuilletti, host haemolymph is the only source of food available for adult females to sustain both reproductive and metabolic needs (Giron et al., 2002). The influence of host-feeding on parasitoid longevity appears to vary as a function of experimental conditions, composition of the host-feeding meal and the ability of females to utilize the ingested nutrients (Giron et al., 2002). Indeed, in some species host-feeding has no effect on longevity, in some it does, whereas in others it does only if a sugar source is also available (reviewed by Jervis \& Kidd, 1986; Heimpel \& Collier, 1996; see also Heimpel et al., 1997).

Models aiming to predict when a parasitoid should trade an opportunity for current reproduction (i.e. laying egg) to feed from the host, and thus increase the chances for future reproduction (i.e. survive and producing eggs), need to quantify the lifetime fitness advantages of each alternative behaviour. Measuring the proximate increase in fitness from laying an egg is, at least a priori, a relatively straightforward task. However, measuring the increase in fitness from feeding is not so simple because it involves a set of complex physiological processes running over different time scales (Rivero \& Casas, 1999b). Such measures can be conducted in two ways: (i) observational or (ii) manipulative approaches. On one hand, observational studies have the advantage of providing a picture of what really happens over a long period without perturbing the system. However, they are unable to explain the physiological processes involved. On the other hand, manipulative studies are helpful in understanding the physiological mechanisms underlying decisions, but have the disadvantage of being conducted usually over a short period of time without taking into account physiological processes occurring over a lifetime period. Indeed, due to the delay required for the nutrients ingested through feeding to be converted into eggs, and the possibility of storage of resources for later use, fitness advantages from a single feeding event are likely to be spread over the lifetime of the parasitoid. Thus, they cannot be measured in terms of the number of eggs laid or produced per unit time, except when using a final count at the end of the life of the parasitoid (Collier, 1995; Heimpel et al., 1997; Rivero \& Casas, 1999b).

In this study, a detailed investigation is made of the lifetime pattern of host-feeding and oviposition in Eupelmus vuilletti (Crawford) (Hymenoptera, Eupelmidae), a parasitoid that feeds and oviposits on third-fourth-instar coleopteran larvae. Eupelmus vuilletti is the only species for which there is quantitative data on food consumption and nutrient allocation to eggs, making it one of the best known parasitoids for the study of host-feeding. Indeed, several key physiological parameters related to the nutritional pay-off of a single host-feeding event have been previously measured, such as the biochemical composition of a single hostfeeding meal and the composition of a single egg (Rivero \& Casas, 1999b; Rivero et al., 2001; Giron et al., 2002; Giron \& Casas, 2003a,b). In the first part of this study, lifetime estimates of host-feeding activity are obtained and explored in relation to consequences for fecundity and longevity. These new results are combined with previous physiological data to determine how the nutritional value of individual host-feeding events influence lifetime fitness. The role of specific host-feeding nutrients in influencing fecundity and longevity is not investigated directly, but was assessed by reference to the results from previous work and by using the known energetic value of nutrients and conversion efficiencies. The generality of the findings is discussed, as well as 
the similarities to and differences from studies on other parasitoid species.

\section{Materials and methods}

Eupelmus vuilletti is a tropical, solitary, host-feeding ectoparasitoid of third- and fourth-instar larvae of Callosobruchus maculatus (Fabricius) (Coleoptera, Bruchidae) infesting Vigna unguiculata (Fabaceae) pods and seeds. Females are synovigenic (i.e. they are born with some immature eggs and need to feed, in this case from the host, to sustain egg production). However, females rarely use the same host for oviposition and for feeding (D. Giron et al., unpublished observations). Culturing and all experimental procedures were carried out in a controlled temperature room under a LD 13:11 h photoperiod, a temperature cycle of $33^{\circ} \mathrm{C}$ (light): $23^{\circ} \mathrm{C}$ (dark), and a constant $75 \%$ relative humidity. All experiments were conducted without any sugar source available and hosts comprised the only source of food for adult parasitoid females.

The complete sequence of host-feeding and oviposition events were recorded in a large series of females over their lifetime. For this purpose, 50 newly emerged females were placed individually in a small Petri dish and given one host per hour for a total of $6 \mathrm{~h}$ (between 09.00 and $15.00 \mathrm{~h}$, corresponding to peak daily activity; D. Giron, personal observation). This was repeated until the females died. The number of eggs laid, the number of hosts fed upon during a the lifespan of a female, and the duration of each host-feeding event were recorded. Hosts provided to females had been previously extracted from the $V$. unguiculata seeds and placed inside a gelatin capsule as previously described Gauthier \& Monge (1999). This system does not alter either the natural behaviour of females or their life expectancy (Giron etal., 2002), and allows experimental control over the number and the developmental stage of the hosts. It also facilitates the recording of the number of eggs laid and the number of host-feeding events.

To determine the quantity of haemolymph consumed during a host-feeding event, 70 newly emerged females were weighed individually (Supermicro Sartorius, Richmond, U.K.) and immediately placed in a small Petri dish with three fourth-instar hosts (as above). Females were observed continuously until a host-feeding event took place. Females were weighed immediately after they finished feeding and the amount of food consumed during their first host-feeding was estimated by subtracting the mass before and after feeding. The duration of each host-feeding event was also recorded.

\section{Results}

Females host-fed, on average, $18.21 \pm 1.87$ times during their life (mean $\pm \mathrm{SE}, n=48$ ) and an average of $1.39 \pm 0.05$ times per day $(n=461)$. The number of host-feeding events performed per day remained approximately constant over the lifespan of females with no clear differences before and after day 7 (Fig. 1).

The mean duration of one host-feeding event was $17.30 \pm 0.84 \mathrm{~min}(n=461)$. The duration of each hostfeeding event positively increased over the lifespan of females (Fig. 2a). This increase in feeding duration divided itself into three phases. During the first 7 days, the duration of host-feeding events showed only a slightly positive increase (slope $=0.87$ ). After 7 days, the duration of hostfeeding events increased rapidly (slope $=3.39$ ) and finally levelled off after approximately 17 days postemergence.

Females wet weight increased on an average of $0.25 \pm 0.17 \mathrm{mg}(n=68)$ per host-feeding event. The amount of host haemolymph consumed increased with increasing duration of host-feeding (Fig. 2b). This relationship was nonlinear (linear regression: $y=0.103 \times \ln (x)+0.096$, $\left.r^{2}=0.25\right)$.

Females lived an average of $13.1 \pm 0.7$ days $(n=48)$ and the mean number of eggs laid during their life was $31.7 \pm 3.2$ eggs $(n=48)$. Fecundity was strongly correlated with the number of host-feeding events performed (linear regression, slope $=1.53, \quad$ intercept $=3.90, \quad r^{2}=0.80, \quad F_{1,47}=174.12$, $P<0.05$ ) (Fig. 3a) as well as longevity (linear regression, slope $=0.31, \quad$ intercept $=7.40, \quad r^{2}=0.79, \quad F_{1,47}=164.25$, $P<0.05$ ) (Fig. 3b). A multiple regression incorporating both longevity and number of host-feeding meals for predicting fecundity (d.f. $=3$, mean-square $=6323.229$, $F=72.149, P=0.000)$ revealed a significant interaction in the effect of both factors on lifetime fecundity, with a predominant effect of host-feeding over longevity (Table 1).

\section{Discussion}

Whether host-feeding provides nutrients exclusively for egg production, exclusively for maintenance, or both, has been an enduring topic in studies of the behavioural and evolutionary ecology of parasitoids. Indeed, this question appears to be crucial for understanding whether the evolutionary trade-off between current and future reproduction (a fundamental constraint on the reproductive success of parasitoids) is mostly limited by the eggs available in the

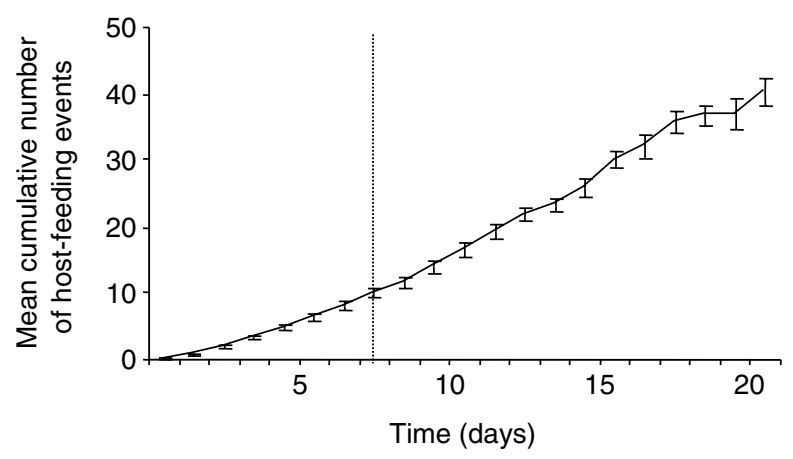

Fig. 1. Mean $( \pm$ SE) cumulative number of host-feeding events performed by Eupelmus vuilletti females over their lifetimes. 

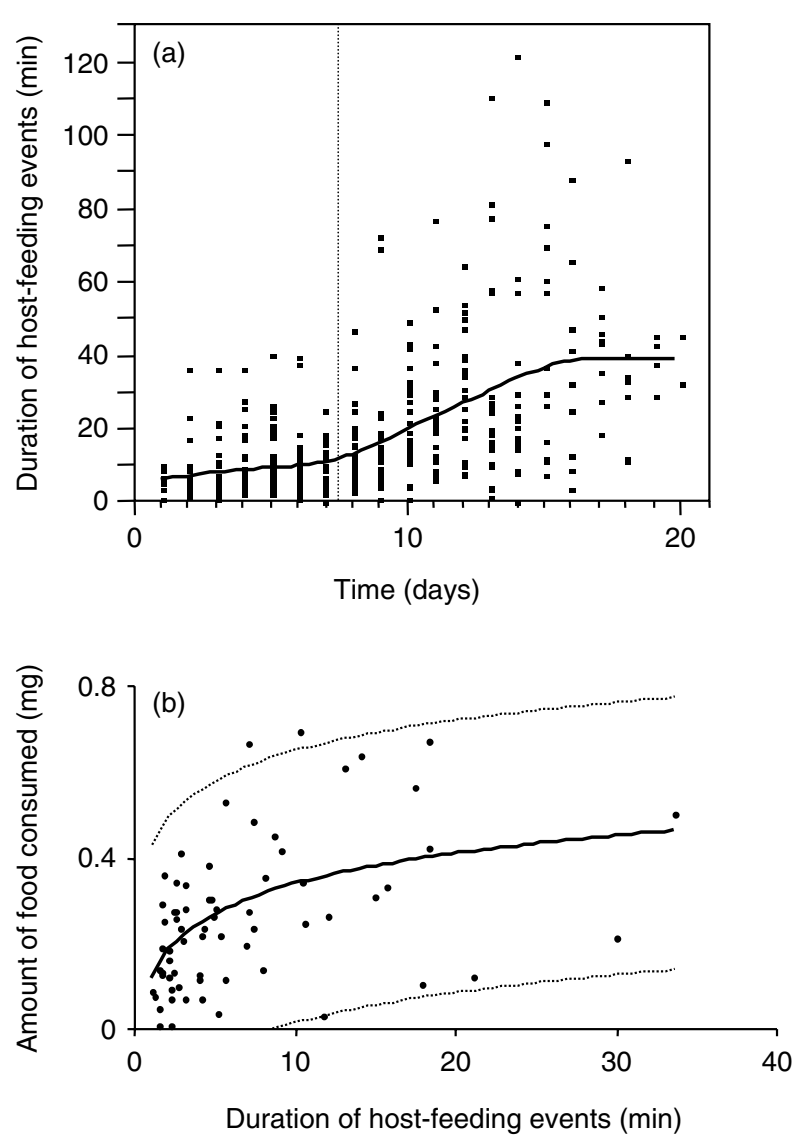

Fig. 2. (a) Duration of host-feeding events over the lifetime of a female. The solid line represents the mean value obtained through a spline regression (Lowess algorithm, tension $=0.5$ ). (b) Amount of host haemolymph consumed as a function of time spent hostfeeding. The solid line represents regression of amount of host haemolymph consumed against time spent host-feeding $\left(y=0.103 \times \ln (x)+0.096, r^{2}=0.25\right)$ and dashed lines are lower and upper $95 \%$ confidence limits.

ovarioles or by the time available to lay them (e.g. Driessen \& Hemerik, 1992; Getz \& Mills, 1996; Rosenheim, 1996, 1999; Heimpel \& Rosenheim, 1998; Heimpel et al., 1998; Mangel \& Heimpel, 1998; Sevenster et al., 1998; Casas etal., 2000; Ellers etal., 2000; Jervis etal., 2001, 2003). Previous studies have largely consisted of comparisons of egg production and longevity in host-fed and unfed females (reviewed by Jervis \& Kidd, 1986; Heimpel \& Collier, 1996). Because most studies have been conducted with sugars provided ad libitum, there are only few estimates of the host-feeding gain per se for any parasitoid species (Heimpel et al., 1994, 1997; Collier, 1995). Thus, there is an important need to study not only the metabolic paths followed by nutrients, but also the physiological budget of parasitoids to enable these evolutionary questions to be answered unequivocally (Rivero \& Casas, 1999a; Rivero et al., 2001; Giron et al., 2002).

The positive correlation between host-feeding and fecundity observed in the present study confirms that host-
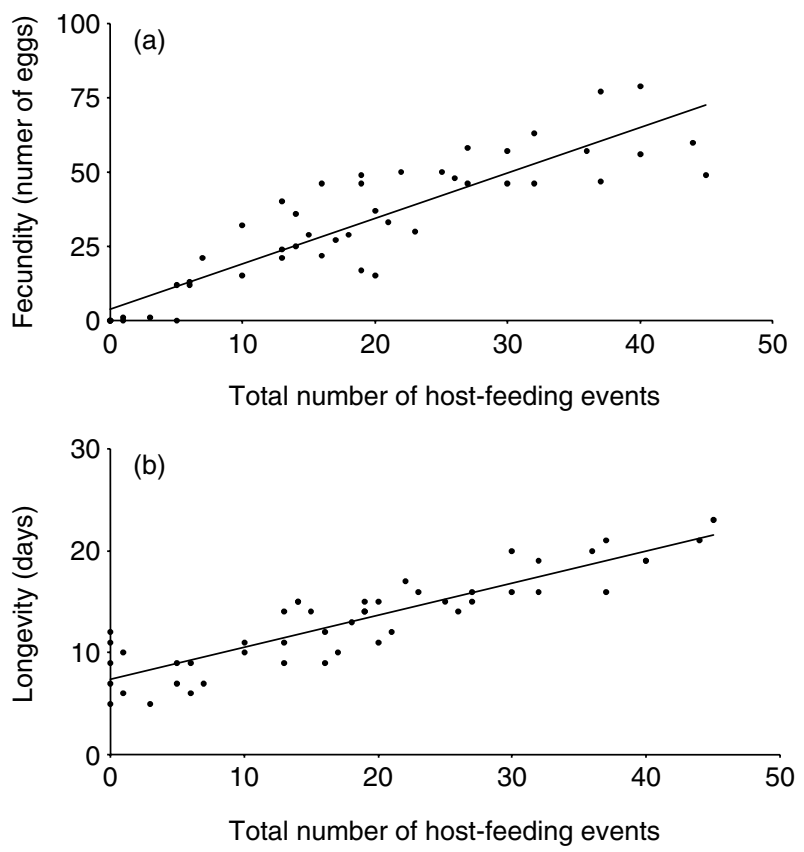

Fig. 3. Lifetime benefits of host-feeding. (a) Relationship between fecundity and number of host-feeding events over the lifetime of a female. (b) Relationship between longevity and number of hostfeeding events.

feeding has a positive influence on egg production. The results also show that $E$. vuilletti females ingest at each host-feeding event an average of $0.25 \mu \mathrm{L}$ of host haemolymph (in insects, haemolymph density is approximately $1 \mathrm{~kg} / \mathrm{L}$; Hoffman, 1995). By using the mean biochemical composition of host haemolymph (Giron et al., 2002) and the average composition of one egg (Giron \& Casas, 2003b), it is possible to estimate that one host-feeding event allows a female to produce a maximum of 1.93 eggs (assuming that eggs are produced exclusively from nutrients gained during host-feeding) (Table 2). This theoretical maximum reproductive host-feeding gain is limited by the small quantity of lipids obtained by a female during host-feeding. Indeed, the quantity of sugars and proteins obtained may lead to the production of a much larger number of eggs.

The estimation of the real reproductive host-feeding gain, obtained by following individual females during all their lives, is 1.53 eggs per host-feeding event realized. This result matches well with the theoretical maximum reproductive host-feeding gain of 1.93 previously obtained. However, the conversion factor of lipids ingested into eggs is known

Table 1. Multiple regression testing for tehe effects of longevity, hostfeeding and their interaction on lifetime fecundity of Eupelmus vuilletti.

\begin{tabular}{llrl}
\hline Source & SE & \multicolumn{1}{l}{$t$} & $P$ \\
\hline Longevity & 0.746 & 2.402 & 0.021 \\
Host-feeding & 0.433 & 4.665 & 0.000 \\
Longevity $\times$ host-feeding & 0.024 & -2.216 & 0.032 \\
\hline
\end{tabular}


Table 2. Maximal potential number of eggs produced from nutrients gained from a single host-feeding event.

\begin{tabular}{llll}
\hline & $\begin{array}{l}\text { Host haemolymph composition } \\
\left(\mu \mathrm{g} \mu \mathrm{L}^{-1}\right)(\text { mean } \pm \mathrm{SE})\end{array}$ & $\begin{array}{l}\text { Parasitoid egg composition } \\
(\mu \mathrm{g})(\text { mean } \pm \mathrm{SE})\end{array}$ & $\begin{array}{l}\text { Maximal potential output } \\
(\text { no. of eggs })\end{array}$ \\
\hline Proteins & $20.45 \pm 0.68$ & $0.29 \pm 0.01$ & 17.62 \\
Sugars & $17.39 \pm 1.35$ & $0.33 \pm 0.01$ & 13.18 \\
Lipids & $2.23 \pm 0.44$ & $0.29 \pm 0.01$ & 1.93 \\
\hline
\end{tabular}

to be less than 1 (as was assumed in the above calculation) and is usually considered to be around 0.8 (McNeillAlexander, 1999). By multiplying the theoretical maximum reproductive host-feeding gain by this conversion factor, 1.54 eggs per host-feeding is obtained. This result closely matches the real reproductive host-feeding gain found in the current study. The increase of fecundity observed in hostfed females can therefore be considered as mainly set by the amount of lipids they obtain by feeding on the host.

The positive correlation between host-feeding behaviour and longevity observed in this study confirms that hostfeeding gain must be considered not only in terms of egg production, but also in terms of survival. By conducting a series of microinjections of host haemolymph sugars into E. vuilletti females, a previous study has shown that host haemolymph sugars (mainly trehalose and sucrose) are the main nutrients responsible for the increase in female longevity in host-fed females, and that one host-feeding event increases the lifetime by 0.33 days (Giron et al., 2002). The results obtained in the present study are 0.31 days of survival obtained per host-feeding event. The lifetime results therefore match well the manipulative results previously obtained. Therefore, host-feeding increases female survival and the lifetime extension can be considered to be mainly due to the intake of sugars.

Although there is now a good understanding of the fate of lipids and sugars, there is no clear picture for proteins. Previous results have shown a clear allocation of proteins to reproduction (Rivero \& Casas, 1999b; Rivero et al., 2001). Most studies assume that synovigenic parasitoids host-feed to sustain the highly protein demands associated with egg production (Jervis \& Kidd, 1986; Heimpel \& Collier, 1996). However, the present results indicate that acquisition of proteins for reproduction is probably not the main purpose of host-feeding behaviour in synovigenic parasitoids. Indeed, an average female gains $90 \mu \mathrm{g}$ of proteins throughout its life (summing over host-feeding events and using known quantities in haemolymph) and invests only onetenth of this in eggs (Giron \& Casas, 2003b).

Because females live for approximately 7 days without food (Giron et al., 2002) and require at least three hostfeeding events to live an additional day, host-feeding should increase after day 7. However, the number of host-feeding events performed per day remains approximately constant over the lifespan of females, with no clear differences before and after day 7. The duration of each host-feeding event during the life of a female is increased from day 7 onwards (Fig. 2b). This behavioural strategy may allow females to obtain the required nutrients and, at the same time, reduce their need to embark on costly and hazardous host foraging trips for food (Flanders, 1942; Bartlett, 1961; Iwasa et al., 1984; Barzman, 1992; Heimpel \& Collier, 1996). The positive relationship between the time spent in host-feeding activities and the weight increase runs in favour of this hypothesis.

Host-feeding gains are thus achieved both in terms of survival and egg production (Fig. 4). Host-feeding contributes to an increased fecundity both by providing nutrients for egg maturation and by increasing longevity, and therefore simply giving the female more time to lay eggs. A multiple regression incorporating both longevity and number of host-feeding meals for predicting fecundity revealed a significant impact of both factors on lifetime fecundity, with a predominant effect of host-feeding over longevity. The combination of manipulative and observational approaches allows a good quantitative estimate of the long-term feeding gains from a single host meal to be obtained. To the authors' knowledge, the only other species for which such estimates are available is Aphytis melinus (Heimpel etal., 1994, 1997; Collier, 1995). Through comparisons between host-fed and control females, it has been estimated that, in A. melinus, host-feeding increases fecundity and that females mature approximately two eggs during a 2-day period (Heimpel etal., 1994; Collier, 1995). The hostfeeding gain is four eggs when integrated over the whole life of the parasitoid (Heimpel etal., 1997). In this species, the increase in lifespan per host-feeding meal is 0.6 days. However, this increase was observed only when an additional

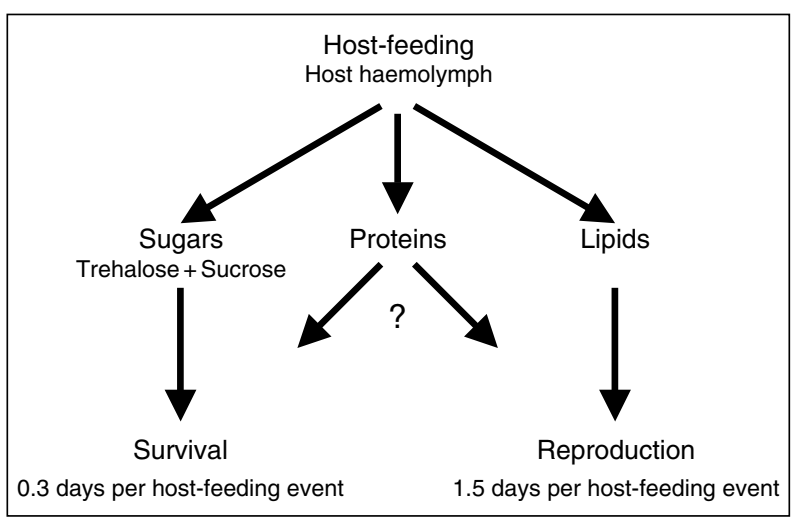

Fig. 4. Schematic diagram showing the state of understanding of the reproductive and survival gains from the nutrients obtained through host-feeding in Eupelmus vuilletti. The fate of the large amounts of proteins obtained is currently unknown, but appears to be of less quantitative importance. 
sugar source was available (Heimpel et al., 1994, 1997; Collier, 1995). In the absence of sugar, lifetime reproductive success is extremely low, even if host-feeding occurs. The possible explanations of this 'sugar dependence' could involve the consumption of a sugar-poor fat body (instead of a sugar-rich haemolymph as in the present case), a low level of host haemolymph sugars or an inability of females to metabolize the ingested sugars (Giron etal., 2002). Further experiments are thus required to estimate hostfeeding gains in the absence of available sugar and in respect of the quantity and quality of food consumed, in Aphytis as well as in a wide variety of parasitoid species.

The results presented here, together with those previously obtained, demonstrate that nutrient acquisition and allocation to reproduction are not only variable, but even change systematically over the lifetime of animal (Giron \& Casas, 2003b). Such gradual changes in food intake during the life history, as a function of either development, reproduction or ageing, is well documented for a variety of insects such as Orthoptera, Coleoptera, Diptera or Hymenoptera (e.g. Bernays \& Chapman, 1972, 1994; Bernays \& Simpson, 1982; Chapman \& de Boer, 1995; Chapman, 1998). By contrast, much less is known about the rules for nutrient allocation to reproduction or survival, except mainly for Lepidoptera (Boggs, 1992, 1997a,b; O’Brien et al., 2000, 2002). A proper quantification of lifetime feeding gains and associated decisions in parasitoids will therefore require estimates at both ends of the life cycle of an animal, leading naturally to dynamic budgets over the entire lifetime of an insect.

\section{Acknowledgements}

We would like to thank M. R. Strand for his helpful comments on a previous version of our manuscript. This study was financed by a PhD scholarship from the French Ministry for education and Research to D.G. Further support was provided by the National Centre of Scientific Research (CNRS).

\section{References}

Bartlett, B.R. (1961) The influence of ants upon parasites, predators and scale insects. Annals of the Entomological Society of America, 54, 543-551.

Bartlett, B.R. (1964) Patterns in the host-feeding habit of adult parasitic Hymenoptera. Annals of the Entomological Society of America, 57, 344-350.

Barzman, M.S. (1992) Host-handling strategies in parasitoids of black scale (Saissetia oleae) (Homoptera: Coccidae). $\mathrm{PhD}$ Thesis, University of California, Berkeley, California.

Bernays, E.A. \& Chapman, R.F. (1972) Meal size in nymphs of Locusta migratoria. Entomologia Experimentalis et Applicata, 15, 399-410.

Bernays, E.A. \& Chapman, R.F. (1994) Host-Plant Selection by Phytophagous Insects Chapman \& Hall, New York.

Bernays, E.A. \& Simpson, S.J. (1982) Control of food intake. Advances in Insect Physiology, 16, 59-118.
Boggs, C.L. (1992) Resource allocation: exploring connections between foraging and life history. Functional Ecology, 6, 508-518.

Boggs, C.L. (1997a) Reproductive allocation from reserves and income in butterfly species with differing adult diets. Ecology, 78, 181-191.

Boggs, C.L. (1997b) Dynamics of reproductive allocation from juvenile and adult feeding: radiotracer studies. Ecology, 78, 192-202.

Casas, J., Nisbet, R.M., Swarbrick, S. \& Murdoch, W.W. (2000) Egg load dynamics and oviposition rate in a wild population of a parasitic wasp. Journal of Animal Ecology, 69, 185-193.

Chan, M.S. (1991) Host-feeding in parasitic wasps: a study of population patterns generated by individual behaviour. $\mathrm{PhD}$ Thesis, Imperial College, University of London, U.K.

Chan, M.S. \& Godfray, H.C.J. (1993) Host-feeding strategies of parasitoid wasps. Evolutionary Biology, 7, 593-604.

Chapman, R.F. (1998) The Insects: Structure and Function, 4th edn. Cambridge University Press, Cambridge.

Chapman, R.F. \& de Boer, G. (1995) Regulatory Mechanism in Insect Feeding Chapman \& Hall, New York.

Collier, T.R. (1995) Adding physiological realism to dynamic state variable models of parasitoid host-feeding. Evolutionary Ecology, 9, 217-235.

Collier, T.R., Murdoch, W.W. \& Nisbet, R.M. (1994) Egg load and the decision to host feed in the parasitoid Aphytis melinus. Journal of Animal Ecology, 63, 299-306.

Doten, S.B. (1911) Concerning the relation of food to reproductive activity and longevity in certain hymenopterous parasites. Technical Bulletin of the Agricultural Experiment Station of the University of Nevada, 78, 1-30.

Driessen, G. \& Hemerik, L. (1992) The time and egg budget of Leptopilina clavipes, a parasitoid of larval Drosophila. Ecological Entomology, 17, 17-27.

Ellers, J., Sevenster, J.G. \& Driessen, G. (2000) Egg load evolution in parasitoids. American Naturalist, 156, 650-665.

Flanders, S.E. (1935) An apparent correlation between the feeding habits of certain pteromalids and the condition of the ovarian follicles. Annals of the Entomological Society of America, 28, 438-444.

Flanders, S.E. (1942) Metaphycus helvolus, an encyrtid parasite of the black scale. Journal of Economic Entomology, 35, 690-698.

Gauthier, H. \& Monge, J.P. (1999) Could the egg itself be the source of the oviposition deterrent marker in the solitary endoparasitoid, Dinarmus basalis? Journal of Insect Physiology, 45, 393-400.

Getz, W.M. \& Mills, N.J. (1996) Host-parasitoid coexistence and egg-limited encounter rates. American Naturalist, 148, 333-347.

Gilbert, F.S. \& Jervis, M.A. (1998) Functional, evolutionary and ecological aspects of feeding-related mouthpart specializations in parasitoid flies. Biological Journal of the Linnean Society, $\mathbf{6 3}$, 495-535.

Giron, D. \& Casas, J. (2003a) Lipogenesis in an adult parasitic wasp. Journal of Insect Physiology, 49, 141-147.

Giron, D. \& Casas, J. (2003b) Mothers reduce egg provisioning with age. Ecology Letters, 6, 273-277.

Giron, D., Rivero, A., Mandon, N., Darrouzet, E. \& Casas, J. (2002) The physiology of host-feeding in parasitic wasps: implications for survival. Functional Ecology, 16, 750-757.

Godfray, H.C. (1994) Parasitoids: Behavioural and Evolutionary Ecology. Princeton University Press, Princeton, New Jersey.

Hagan, K.S. (1986) Ecosystem analysis: Plant cultivars (HPR), entomophagous species and food supplements. Interactions of Plant Resistance and Parasitoids and Predators of Insects (ed. by D. J. Boethel and R. D. Eikenbary), pp. 151-197. John Wiley \& Sons, U.K. 
Heimpel, G.E. \& Collier, T.R. (1996) The evolution of host-feeding behaviour in insect parasitoids. Biological Reviews, 71, 373-400.

Heimpel, G.E. \& Rosenheim, J.A. (1998) Egg limitation in parasitoids: a review of the evidence and a case study. Biological Control, 11, 160-168.

Heimpel, G.E., Rosenheim, J.A. \& Adams, J.M. (1994) Behavioural ecology of host-feeding in 'Aphytis' parasitoids. Norwegian Journal of Agricultural Sciences, 16, 101-115.

Heimpel, G.E., Rosenheim, J.A. \& Kattari, D. (1997) Adult feeding and lifetime reproductive success in the parasitoid Aphytis melinus. Entomologia Experimentalis et Applicata, 83, 305-315.

Heimpel, G.E., Mangel, M. \& Rosenheim, J.A. (1998) Effects of time limitation and egg limitation on lifetime reproductive success in parasitoids. American Naturalist, 54, 465-476.

Hoffman, K.H. (1995) Stoffwechsel. Physiologie der Insekten (ed. by M. Gewecke), pp. 1-60. Gustav Fisher Verlag, Germany.

Houston, A.I., McNamara, J.M. \& Godfray, H.C.J. (1992) The effect of variability on host-feeding and reproductive success in parasitoids. Bulletin of Mathematical Biology, 54, 465-476.

Iwasa, Y., Suzuki, Y. \& Matsuda, H. (1984) Theory of oviposition strategy of parasitoids. Theoretical Population Biology, 26, 205-227.

Jervis, K.A., Ferns, P.N. \& Heimpel, G.E. (2003) Body size and the timing of egg production in parasitoid wasps: a comparative analysis. Functional Ecology, 17, 375-383.

Jervis, M.A. \& Kidd, N.A.C. (1986) Host-feeding strategies in hymenopteran parasitoids. Biological Reviews, 61, 395-434.

Jervis, M.A. \& Kidd, N.A.C. (1996) Phytophagy. Insect Natural Enemies Practical Approaches to Their Study and Evaluation (ed. by M. A. Jervis and N. A. C. Kidd), pp. 375-394. Chapman \& Hall, U.K.

Jervis, M.A. \& Kidd, N.A.C. (1999) Parasitoid adult nutritional ecology: implications for biological control. Theoretical Practical Approaches to Biology Control (ed. by B. A. Hawkins and H. V. Cornell), pp. 131-151. Cambridge University Press, Cambridge.

Jervis, M.A., Kidd, N.A.C. \& Walton, M. (1992) A review of methods for determining dietary range in adult parasitoids. Entomophaga, 4, 565-574.

Jervis, M.A., Kidd, N.A.C., Fitton, M.G. et al. (1993) Flowervisiting by hymenopteran parasitoids. Journal of Natural History, 27, 67-105.

Jervis, M.A., Kidd, N.A.C. \& Heimpel, G.E. (1996) Parasitoid adult feeding behaviour and biocontrol - a review. Biocontrol News and Information, 17, 11-22.

Jervis, M.A., Heimpel, G.E., Ferns, P.N. et al. (2001) Life-history strategies in parasitoid wasps: a comparative analysis of 'ovigeny'. Journal of Animal Ecology, 70, 442-458.

Kidd, N.A.C. \& Jervis, M.A. (1989) The effects of host-feeding behaviour on the dynamics of parasitoid-host interactions, and the implications for biological control. Researches on Population Ecology, 31, 235-274.
Kidd, N.A.C. \& Jervis, M.A. (1991a) Host-feeding and oviposition strategies of parasitoids in relation to host stage. Researches on Population Ecology, 33, 13-28.

Kidd, N.A.C. \& Jervis, M.A. (1991b) Host-feeding and oviposition by parasitoids in relation to host stage: consequences for parasitoid-host population dynamics. Researches on Population Ecology, 33, 87-89.

Krivan, V. \& Sirot, E. (1997) Searching for food or hosts: the influence of parasitoids behaviour on parasitoid-host dynamics. Theoretical Population Biology, 51, 201-209.

Leius, K. (1961) Influence of various foods on fecundity and longevity of adults of Scambus buolianae (Hymenoptera: Ichneumonidae). Canadian Entomologist, 93, 1079-1084.

Mangel, M. (1989) Evolution of host selection in parasitoids: does the state of the parasitoid matter? American Naturalist, 133, 688-703.

Mangel, M. \& Heimpel, G.E. (1998) Reproductive senescence and dynamic oviposition behaviour in insects. Evolutionary Ecology, 12, 871-879.

McNeill-Alexander, A.R. (1999) Energy for Animal Life. Oxford University Press, Oxford.

Murdoch, W.W. (1990) Population regulation in theory and practice. Ecology, 75, 271-285.

O’Brien, D.M., Schrag, D.P. \& Martinez del Rio, C. (2000) Allocation to reproduction in a hawkmoth: a quantitative analysis using stable carbon isotopes. Ecology, 81, 2822-2831.

O'Brien, D.M., Fogel, M.L. \& Boggs, C.L. (2002) Renewable and non-renewable resources: amino acid turnover and allocation to reproduction in Lepidoptera. Proceedings of the National Academy of Sciences of the U.S.A., 99, 4413-4418.

Rivero, A. \& Casas, J. (1999a) Incorporating physiology into parasitoid behavioural ecology: the allocation of nutritional resources. Researches on Population Ecology, 41, 39-45.

Rivero, A. \& Casas, J. (1999b) Rate of nutrient allocation to egg production in a parasitic wasp. Proceedings of the Royal Society of London, B, 266, 1169-1174.

Rivero, A., Giron, D. \& Casas, J. (2001) Lifetime allocation of juvenile and adult nutritional resources to egg production in a holometabolous insect. Proceedings of the Royal Society of London, B, 268, 1231-1237.

Roff, D.A. (2002) Life History Evolution. Sinauer Associates Inc., Sunderland, Massachusetts.

Rosenheim, J.A. (1996) An evolutionary argument for egg limitation. Evolution, 50, 2089-94.

Rosenheim, J.A. (1999) The relative contributions of time and eggs to the cost of reproduction. Evolution, 53, 376-385.

Sevenster, J.G., Ellers, J. \& Driessen, G. (1998) An evolutionary argument for time limitation. Evolution, 52, 1241-1244.

Accepted 30 June 2004 